\title{
APLIKASI OBJEK WISATA 3D AUGMENTED REALITY BERBASIS MOBILE
}

\author{
Yoyon Efendi' ${ }^{1}$ Agung Marinda², Lusiana $^{3}$ \\ ${ }^{1}$ Teknologi Informasi, ${ }^{2,3}$ Teknik Informatika, STMIK Amik Riau \\ Jln. Purwodadi Indah Km 10 Pekanbaru, 28294 \\ ${ }^{1}$ yoyonefendi@stmik-amik-riau.ac.id, ${ }^{2}$ agungmarinda@stmik-amik-riau.ac.id, \\ 3 lusiana@stmik-amik-riau.ac.id
}

\begin{abstract}
Riau Province has various natural attractions such as Siak Palace, Sang Nila Utama Museum and Muara Takus Temple. At the Siak Palace, currently the information obtained is only in the form of websites and brochures. But information is not enough, a tourist attraction will be more interesting if the public can see and get the tour object directly. Then technology is needed that can be enjoyed by visitors through cellular media such as Augmented Reality. Making begins with collecting Riau tourism data that will be made as a model using software sketches. Then it is processed again using Unity by using markerless using Vuforia. The features in this application display some detailed information on the Siak 3D Palace. With the existence of mobile-based Augmented Reality technology, it is easier for people who want to travel to see buildings and historical objects at the Siak Palace.
\end{abstract}

Keywords : Istana Siak, Augmented Reality, Mobile

\begin{abstract}
Abstrak
Provinsi Riau memiliki objek wisata keindahan alam yang beraneka ragam seperti Istana Siak, Museum Sang Nila Utama dan Candi Muara Takus. Pada istana siak, saat ini informasi yang didapat hanya berupa website dan brosur. Namun informasi saja tidak cukup, suatu objek wisata akan lebih menarik jika masyarakat dapat melihat dan mengamati langsung obek wisata tersebut. Maka diperlukan sebuah teknologi yang dapat dinikmati pengunjung melalui media mobile seperti Augmented Reality. Pembuatan diawali dengan mengumpulkan data objek wisata Riau yang akan dibuat sebagai model menggunakan software sketchup. Selanjutnya diolah lagi menggunakan Unity dengan merancang markerless menggunakan Vuforia. Fitur dalam aplikasi ini menampilkan beberapa detail informasi Istana Siak secara 3D. Dengan adanya teknologi Augmented Reality berbasis mobile, memudahkan masyarakat yang ingin berwisata agar dapat melihat bangunan dan benda-benda sejarah yang berada di Istana Siak.
\end{abstract}

Kata kunci : Istana Siak, Augmented Reality, Mobile.

\section{PENDAHULUAN}

Provinsi Riau memiliki objek wisata baik buatan dan keindahan alam seperti Istana siak, Museum sang nila Utama, Candi Muara Takus dan lain-lain. Kabupaten Siak merupakan salah satu Kabupaten dengan ibu kotanya " Siak Sri Indrapura " yang ada di Provinsi Riau. Kabupaten ini sejak dulunya dikenal dengan Kerajaan Siak yang megah. Hal ini dapat dibuktikan dengan masih banyaknya situs-situs sejarah yang terdapat di Kabupaten Siak yang ada hingga saat ini. Potensi sejarah ini menjadi salah satu aset besar bagi Siak untuk mengembangkan kepariwisataan Siak[1]. Salah satunya yang paling terkenal adalah Istana Siak 
Istana Siak merupakan peninggalan bersejarah dari Kerajaan Siak yang dahulunya dihuni oleh Sultan Siak. Istana Siak ini terletak di daerah Siak, Provinsi Riau. Namun sangat disayangkan karena sekarang ini tidak banyak masyarakat yang tertarik untuk mengetahui sejarah dan informasi tentang Istana Siak. Hingga saat ini informasi wisata provinsi Riau hanya brosur, website ataupun blog. Diperlukan inovasi dalam promosi objek wisata yang membantu meningkatkan kunjungan. Promosi adalah segala bentuk komunikasi yang digunakan untuk menginformasikan (to inform), membujuk (to persuade), atau mengingatkan (to remind), orangorang tentang produk yang dihasilkan organisasi, individu, ataupun rumah tangga[2]. Selebihnya, untuk mendapatkan informasi lainnya para wisatawan harus melihat langsung atau mengunjunginya. Diperlukan media yang dapat memberikan gambaran kondisi dan apa yang ditemui di objek wisata tersebut. Salah satu media yang dapat digunakan berupa teknologi aplikasi mobile.

Hasil aplikasi berupa aplikasi Augmented Reality (AR) menggunakan metode Markerless User Defined Target (UDT) yang mampu menampilkan istana siak secara 3D tanpa menggunakan marker khusus pada perangkat android. Dengan metode Markerless User Defined Target yang didalamnya terdapat fitur berbasis ground plane yang dapat memudahkan dalam pemanfaatan teknologi Augmented Reality objek wisata Riau tanpa harus menggunakan marker.

\section{TINJUAN PUSTAKA}

Augmented Reality adalah sebuah teknologi yang menggabungkan dunia nyata dengan dunia virtual sehingga kita dapat berinteraksi secara langsung dengan objek [3]. Berdasarkan teknik pendetksian objek (object tracking techniques) sistem augmented dibagi menjadi 3 jenis yaitu positioning, marker dan markerless[4].

Augmented reality merupakan sebuah teknologi terobosan di bidang teknologi multimedia, dimana memanfaatkan objek 3D terangkat seolah-olah tampak seperti nyata. Penerapan teknologi ini sudah sampai pada tahapan penggunaan di PC hingga perangkat mobile[5]. Aplikasi mobile yang ada ini mampu menampilkan informasi wisata yang dapat diakses kapanpun dan dimanapun lewat perangkat gadget. Namun informasi saja tidak cukup, suatu objek wisata akan lebih menarik jika masyarakat dapat melihat dan mengamati langsung objek wisata dengan Augmented Reality.

Maka dari itu dibutuhkan teknologi Augmented Reality yang dapat menggabungkan benda maya dua dimensi dan ataupun tiga dimensi ke dalam sebuah lingkungan nyata lalu memproyeksikan benda-benda maya tersebut dalam waktu nyata. Aplikasi ini bertujuan mempermudah wisatawan yang berkunjung ke Riau untuk menemukan lokasi wisata serta memberikan informasi mengenai wisata terkait dalam bentuk Augmented Reality. Aplikasi ini juga dapat digunakan sebagai sarana dalam mempromosikan kepariwisataan Provinsi Riau oleh dinas pariwisata terkait.

Pada aplikasi ini juga akan dirancang untuk melihat informasi detail objek wisata dan menampilkan suatu objek secara 3D (3 Dimensi). Objek 3D atau objek tiga dimensi adalah sebuah objek / ruang yang memiliki panjang, lebar dan tinggi yang memiliki bentuk. 3D tidak hanya digunakan dalam matematika dan fisika saja melainkan dibidang grafis, seni, animasi, komputer dan lain-lain. Dalam grafik komputer 3D, modeling 3D adalah suatu proses menciptakan objek 3D yang ingin dituangkan dalam bentuk visual nyata melalui perangkat lunak tertentu[6].

Pada perangkat mobile pengguna akan lebih memudahkan mengetahui objek-objek benda di Istana Siak secara 3D yang akan dirancang dengan teknologi Augmented Reality. Aplikasi Augmented Reality pada umumnya menggunakan marker khusus atau buku sebagai media dari sekumpulan marker (marker based augmented reality). Marker khusus tersebut mengakibatkan aplikasi augemented reality menjadi ketergantungan karena aplikasi hanya dapat dijalankan jika marker tersedia. Markerless augmented reality akan sangat praktis jika dapat diterapkan pada augmented reality menggunakan smartphone android karena aplikasi dapat dijalankan dimanapun tanpa perlu mencetak marker[7]

\section{METODOLOGI PENELITIAN \\ 3.1 Perancangan Interaktif}

Perancangan desain interaktif meliputi desain penggunaan aplikasi Augmented Reality, dan desain Implementasi. 


\section{Menu Utama}

Dengan penggunaan menu maka pengguna akan lebih mudah dalam menggunakan aplikasi Augmented Reality Istana Siak secara 3D. Menu utama terdapat Opening, animasi 3D dan Closing.

\section{a. Opening}

Tampilan pertama yang di sajikan pada aplikasi Augmented Reality Istana Siak ini adalah tampilan opening. Dapat dilihat pada gambar 3.1 di bawah ini :

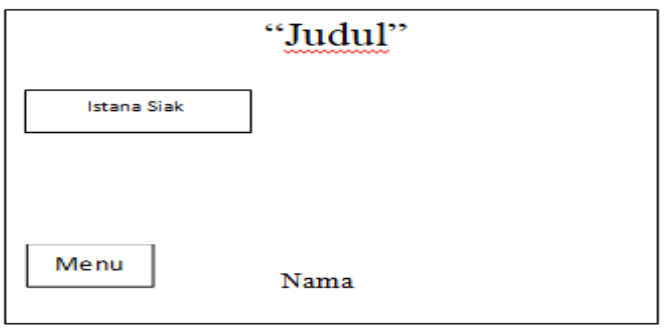

\section{b. Animasi 3D}

Gambar 3.1 Opening

Pada tampilan ini akan menyajikan Istana Siak yang telah discan dengan teknik ground plane, tampilan ini terdapat beberapa button Icon mulai dari deksripsi, objek benda, sound, lantai 1 , lantai 2 dan lokasi. Dapat dilihat pada gambar 3.2 di bawah ini :

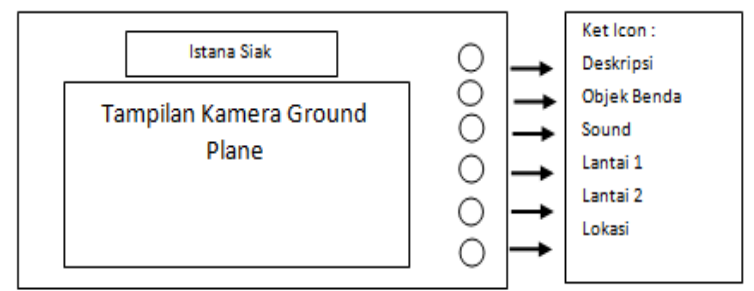

Gambar 3.2 Animasi 3D

\section{c. Closing}

Pada tampilan ini adalah sesi dari penutup pada aplikasi Augmented Reality Istana Siak. Dapat di lihat pada gambar 3.3 di bawah ini :

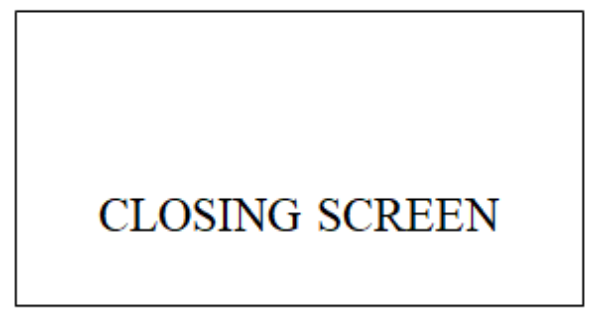

Gambar 3.3 Closing

\subsection{Alur Kerja Perangat Lunak}

Aplikasi yang akan dibangun adalah suatu aplikasi mobile yang dijalankan pada smartphone yang telah mendukung Augmented Reality. Berikut ini adalah gambaran umum dari sistem.

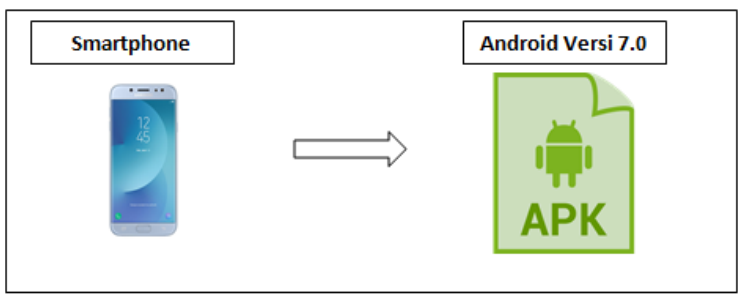

Gambar 3.4 Alur Kerja Perangkat Lunak

Alur kerja perangkat lunak yang di tunjukan dari Gambar 3.4 menunjukan bahwa untuk menjalan aplikasi Augmented Reality Istana Siak 3D, haruslah didukung oleh smartphone yang menggunakan sistem operasi Android Versi 7.0 dan mendukung dalam menjalankan aplikasi Augmented reality.

\subsection{Proses Desain Aplikasi}

Proses desain aplikasi menjelaskan tahapan dari pembuatan aplikasi mulai dari awal pembuatan objek tiga dimensi sampai proses membuat aplikasi Augmented Reality Istana Siak 3D ( tiga dimensi). Berikut ini adalah gambaran dari proses desain aplikasi.

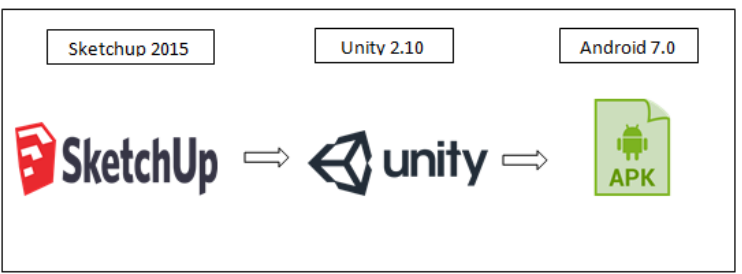

Gambar 3.5 Proses Desain Aplikasi

Dari gambar proses desain aplikasi yang di tunjukan Gambar 3.5 menunjukan bahwa proses desain dimulai dengan membuat object animasi menggunakan aplikasi Sketchup. Aplikasi Sketchup digunakan sebagai media untuk mengolah objek tiga dimensi, dimulai dengan objek cube yang akan di olah sehingga menyerupai bentuk objek yang di inginkan. Setelah menyerupai bentuk animasi 3D kemudian menambahkan detail-detail objek seperti teksture atau warna dari objek. Agar dapat di 
import kedalam Unity 3D simpan file dengan format (.obj).

Selanjutnya tahapan menggabungkan setiap model object 3D menjadi scene sebuah rancangan objek bangunan dan benda tiga dimensi dengan menggunakan software Unity 3D. Selanjutnya import file objek 3d yang telah dibuat dengan sketchup, kemudian memindahkan objek kedalam jendela kerja unity dengan click and drop objek. Selanjutnya export project yang telah dibuat kedalam apk android dengan format (.apk). Tahapan selanjutnya manjalankan file yang telah di export dengan smarphone.

\subsection{Hirarki Menu}

Hirarki menu adalah gambaran menu yang dapat diakses oleh user. Adapun gambar hirarki menu program dapat dilihat pada gambar 3.6 dibawah ini :

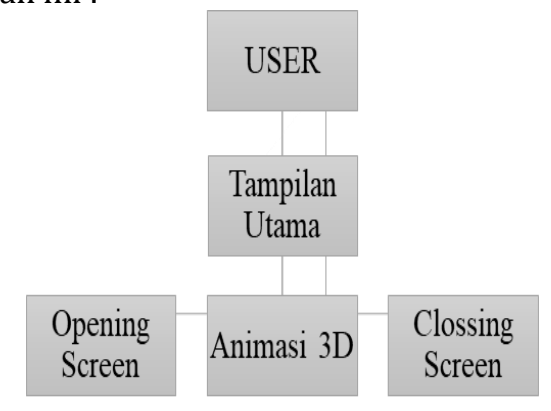

Gambar 3.6 Hirarki Menu Aplikasi

\section{HASIL DAN PEMBAHASAN}

Dalam rancangannya menggunakan Google Sketchup untuk membangun objek dalam bentuk tiga dimensi. Dalam perancangannya aplikasi tersebut berhubungan dengan format yang sesuai dengan aplikasi Unity Engine.

Untuk dapat di akses di perlukan smartphone yang sudah mampu menjalankan Augmented Reality dan telah mampu menjalankan fitur Ground Plane dimana aplikasi tersebut akan menampilkan hasil perancangan pada bidang datar yang akan dideteksi secara otomatis Spesifikasi perangkat lunak yang dibutuhkan agar untuk membangun aplikasi dan membuat aplikasi ini berjalan optimal sebagai berikut :

1. Aplikasi Google Sketchup 2015

2. Aplikasi Unity $3 D$ versi 2.5 (64-bit)

3. Operating sistem dengan spesifikasi windows 864 Bit.

4. Android 7.0 Nougat

\subsection{Objek 3D pada Google Sketchup}

Untuk menghasilkan objek 3D yang akan ditampilkan pada sistem dilakukan perancangan pada aplikasi Google Sketchup. Objek 3D didesain sedemikian rupa agar dapat mewakili objek aslinya yang akan ditampilkan pada aplikasi. Istana Siak terdiri dari 3 tampilan yaitu Tampilan keseluruhan secara lengkap dengan halaman sekitar, lantai 1 dilengkapi dengan beberapa artefak atau objek interior dan lantai 2 lengkap dengan interior.

\section{a. Istana Siak secara keseluruhan}

Tampilan yang terlihat Istana Siak secara keseluruhan dengan halaman. Dapat dilihat pada gambar 4.1 dibawah ini:

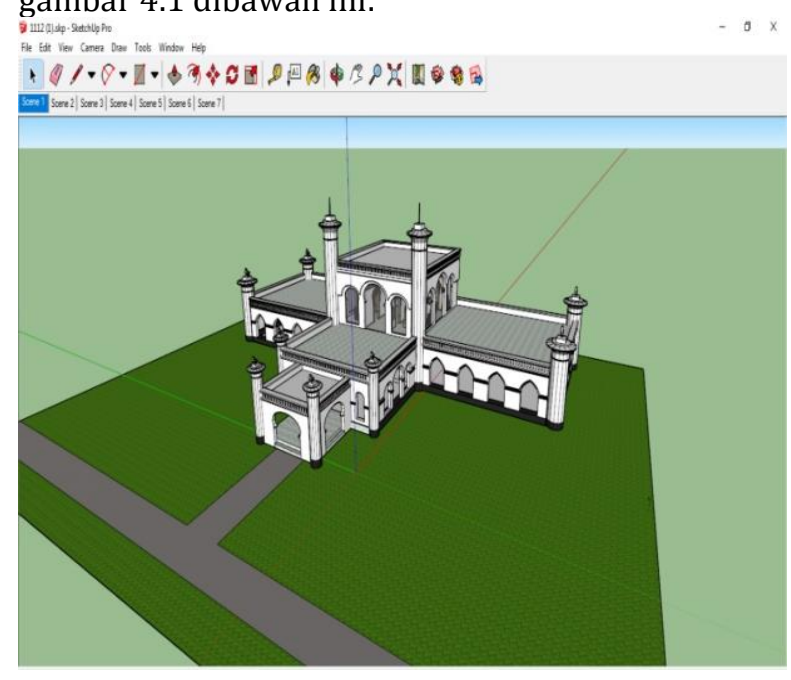

Gambar 4.1 Istana Siak Keseluruhan

\section{b. Istana Siak Lantai 1}

Tampilan pada lantai 1 dilengkapi dengan objek objek interior yang merupakan gambaran langsung pada kondisi aslinya. Dapat dilihat pada gambar 4.2 sebagai berikut: 


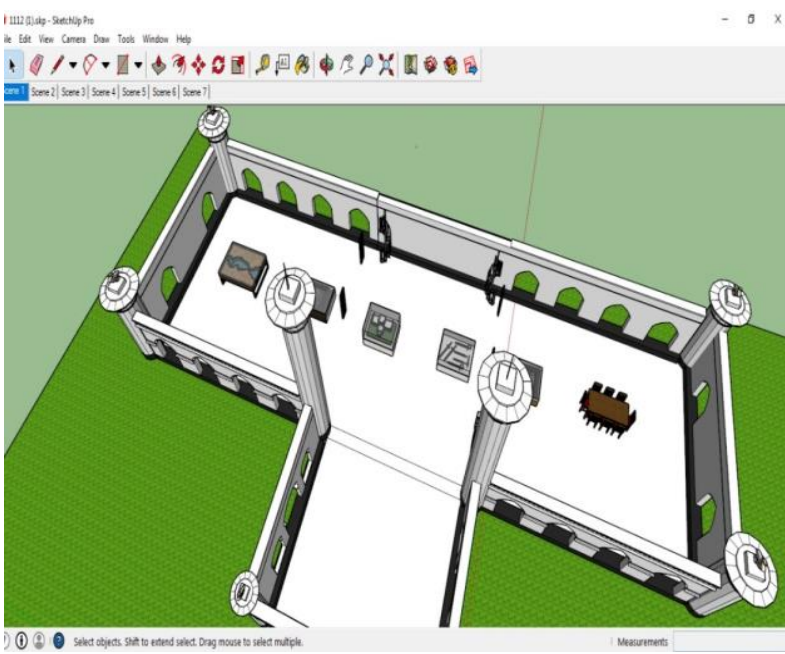

Gambar 4.2 Lantai 1 dengan interior

Pada lantai 1 terdapat objek interior didesain sedetail mungkin agar dapat menyerupai objek aslinya. Objek cermin ini menjadi salah satu incaran para wisatawan setiap kali berkunjung ke istana seperti gambar 4.3 dibawah ini:

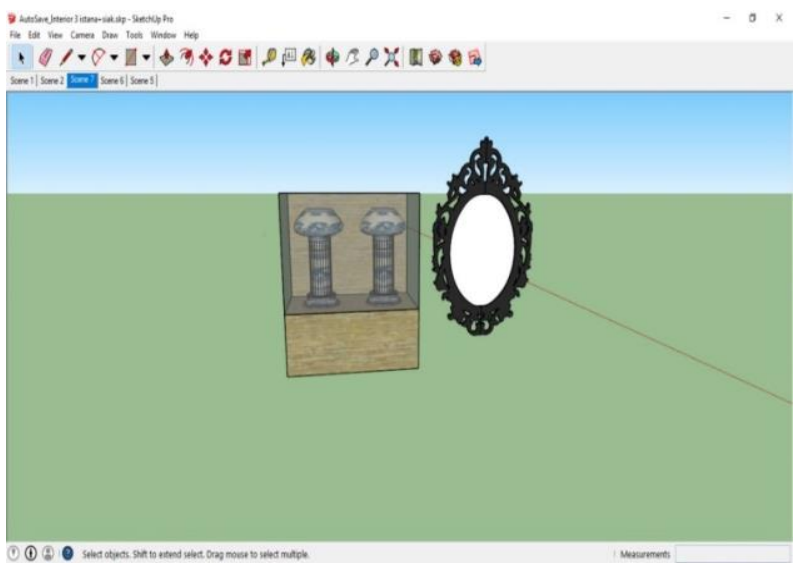

Gambar 4.1 Desain Objek Interior

\section{c. Istana Siak Lantai 2}

Tampilan pada lantai 2 lengkap dengan interior yang didesain menyerupai kondisi aslinya lengkap dengan ornamen ornament didinding agar menghasilkan objek yang serupa dengan aslinya. Dapat dilihat pada gambar 4.4 sebagai berikut:

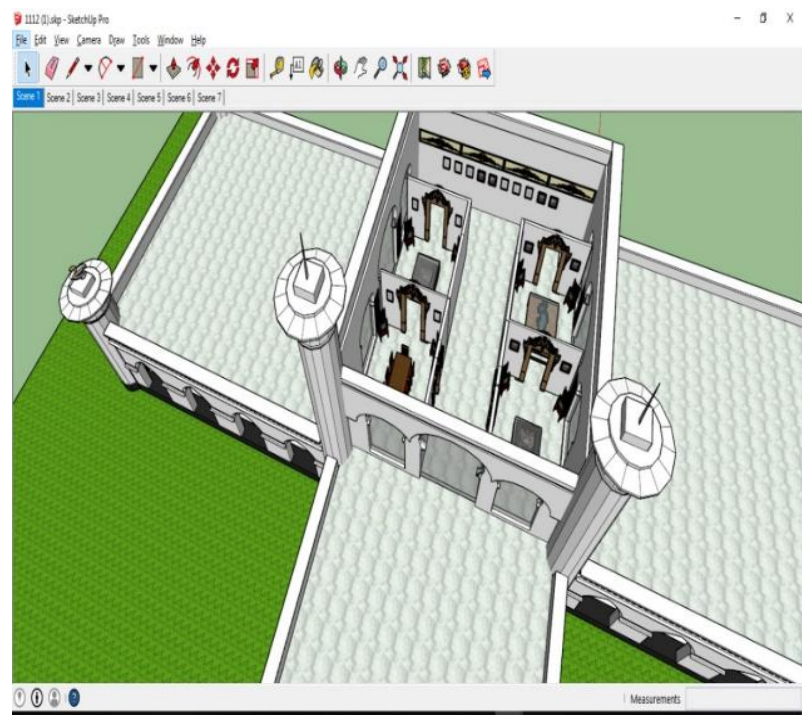

Gambar 4.4 Lantai 2 Dengan Interior

Objek 3D istana siak yang sudah dibangun pada aplikasi Sketchup diexport menjadi objek dan kemudian diimport pada aplikasi Unity dan ditempatkan tepat diatas Ground Plane.

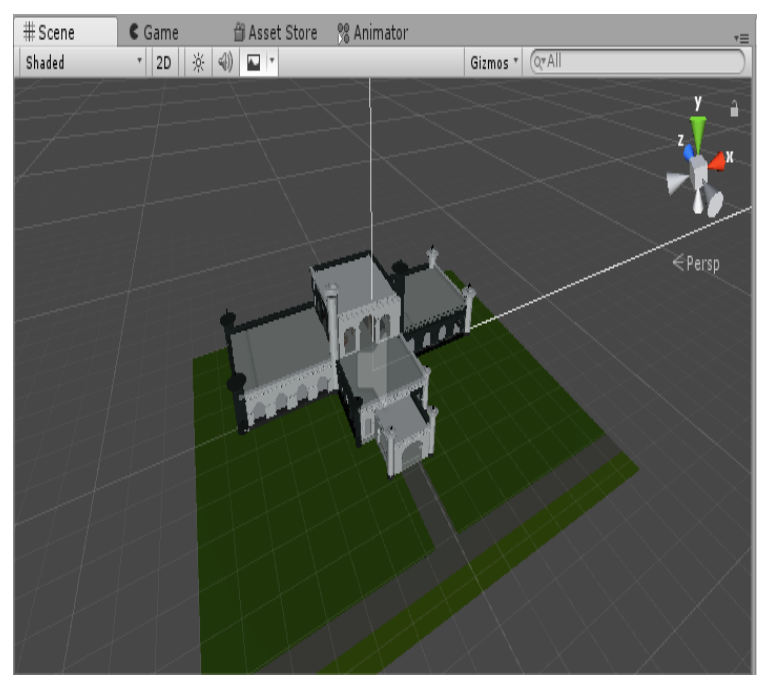

Gambar 4.5 Importing Objek 3D pada aplikasi

Sama halnya dengan Objek 3D Istana Siak, pada objek interior diexport menjadi objek dengan ekstention Obj dan kemudian diimport pada aplikasi Unity dan ditempatkan tepat diatas Ground Plane, yang nantikan akan ditampilkan menggunakan tombol navigasi. 


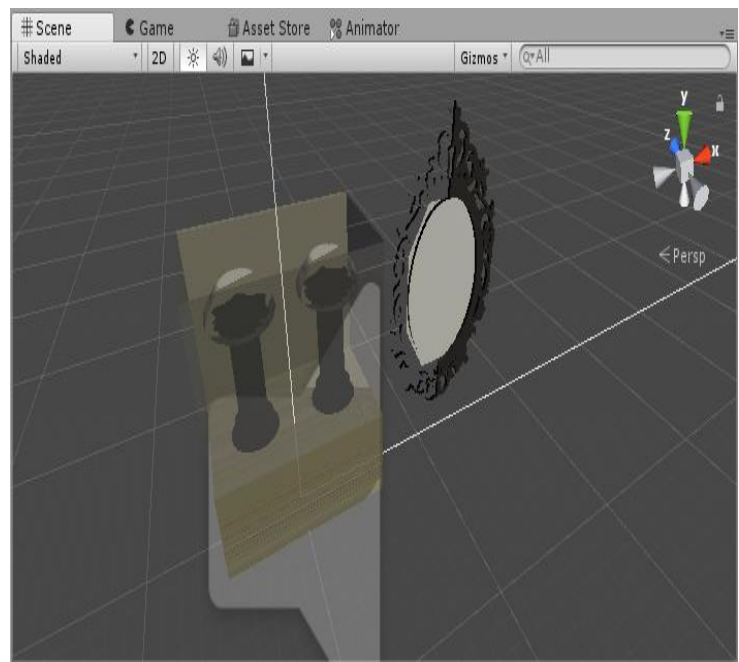

Gambar 4.6 Importing Objek 3D Interior

\subsection{Aplikasi Berbasis Ground Plane}

Pada tahapan Aplikasi Berbasis Ground Plane, Aplikasi dirancang menggunakan aplikasi Unity Engine dan Vuforia 7.2 yang telah menyediakan fiture Ground Plane, dimana Ground Plane merupakan sebuah fiture yang dapat mendeteksi suatu bidang datar secara otomatis dengan demikian objek 3D yang telah di desain sebelumnya akan ditampilkan pada Ground Plane. Pada bagian menu utama di rancang dengan menampilkan 1 button, dapat dilihat pada gambar 4.7 sebagai berikut:

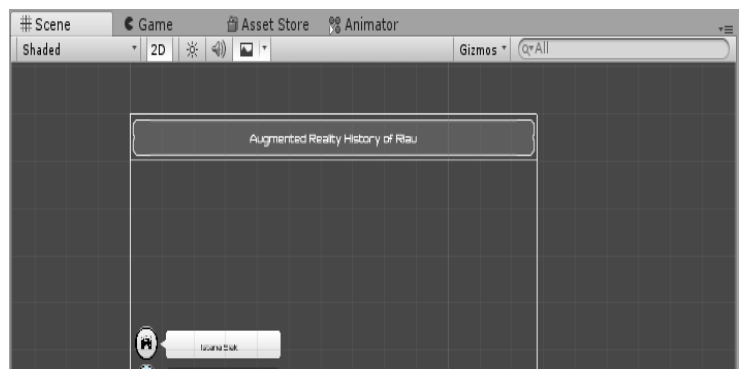

Gambar 4.7 Menu Utama

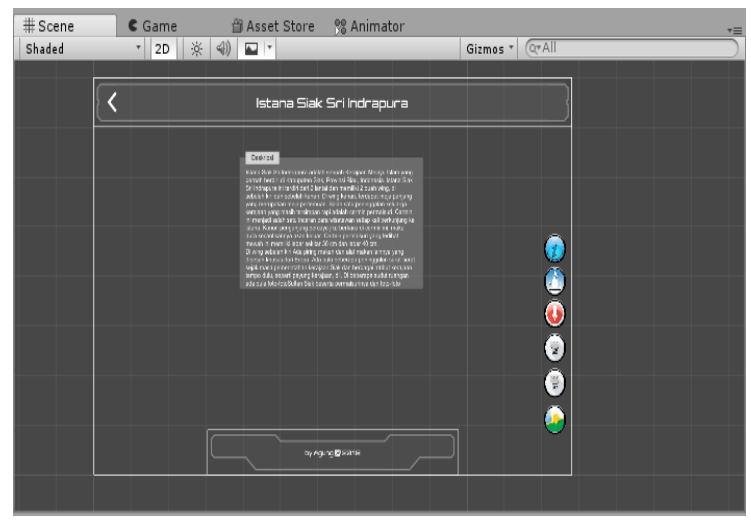

Gambar 4.8 Menu Objek Istana Siak

Setiap scene yang diracang akan terdapat menu navigasi pada sebelahkan dan panel deskripsi ditengah - tengah scene.

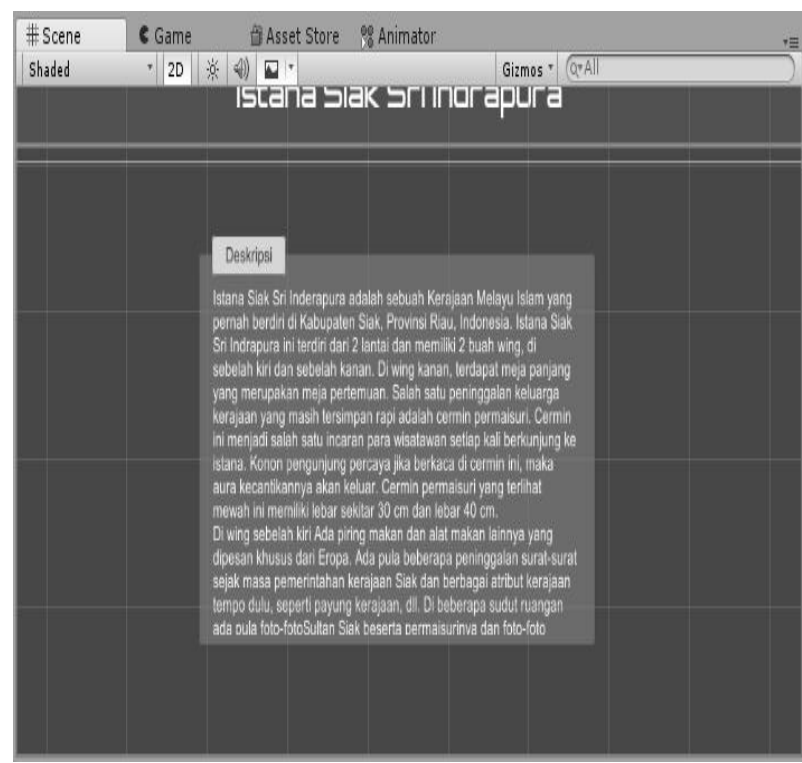

Gambar 4.9 Deskripsi Objek

Panel deskripsi diposisikan pada tengah scene agar dapat dengan mudah terbaca oleh pengguna, dan pada panel deskripsi dapat discrol atas dan bawah sehingga deskripsi setiap objek yang ditampilkan akan dapat terbaca secara keseluruhan. 


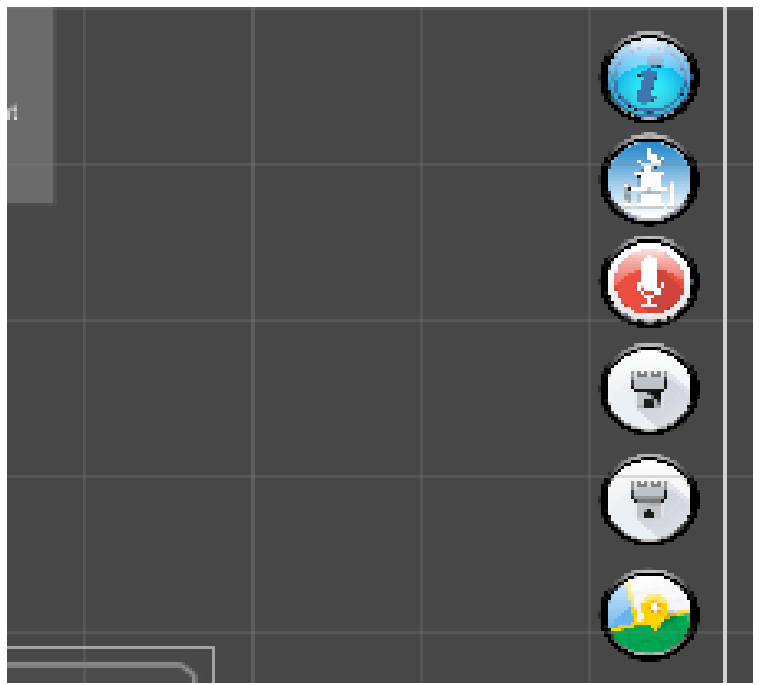

Gambar 4.10 Меnu

Menu navigasi diposisikan pada sebelah kanan layar, dimana setiap button navigasi memiliki fungsi masing masing dan setiap scene memiliki jumlah button yang berbeda.

Tabel 1. Menu Sistem

\begin{tabular}{|c|c|c|}
\hline No & Icon & Deksripsi \\
\hline 1 & & $\begin{array}{l}\text { Menampilkan menu } \\
\text { navigasi utama, yang } \\
\text { befungsi untuk } \\
\text { mengarahkan } \\
\text { pengguna pada scene } \\
\text { objek yang diinginkan. }\end{array}$ \\
\hline 2 & & $\begin{array}{l}\text { Button navagasi yang } \\
\text { berfungsi untuk } \\
\text { membuka scene objek } \\
\text { Istana Siak. }\end{array}$ \\
\hline 3 & & $\begin{array}{l}\text { Button navagasi yang } \\
\text { berfungsi untuk } \\
\text { menampilkan dan } \\
\text { menyembunyikan } \\
\text { deskripsi dari setiap } \\
\text { objek yang } \\
\text { ditampilkan }\end{array}$ \\
\hline 6 & & $\begin{array}{l}\text { Button navagasi yang } \\
\text { berfungsi untuk } \\
\text { menampilkan dan } \\
\text { menyembunyikan } \\
\text { lantai pada objek } \\
\text { Istana Siak }\end{array}$ \\
\hline
\end{tabular}

\begin{tabular}{|l|l|l|}
\hline 7 & $\begin{array}{l}\text { Button navagasi yang } \\
\text { berfungsi dan } \\
\text { menampilkan untuk } \\
\text { menyembunyikan } \\
\text { objek interior yang } \\
\text { telah disediakan }\end{array}$ \\
\hline 8 & $\begin{array}{l}\text { Button navagasi yang } \\
\text { berfungsi untuk } \\
\text { memulai penjelasan } \\
\text { suara dari setiap objek }\end{array}$ \\
\hline 9 & $\begin{array}{l}\text { Button navagasi yang } \\
\text { berfungsi untuk } \\
\text { mengarahkan } \\
\text { pengguna kepada } \\
\text { lokasi objek }\end{array}$ \\
\hline
\end{tabular}

\section{3 Hasil dan Implementasi}

Pada tahapan hasil dan implementasi aplikasi diujikan pada smartphone yang telah dapan menjalakan fiture Ground Plane dari Vuforia, dimana aplikasi diujikan pada smartphone Samsung J7 Pro dan Versi Android 7.0 Nougat, selain smartphone tersebut aplikasi hanya dapat berjalan pada smartphone yang telah masuk didaftar Vuforia Fusion Supported Device yang dapat dilihat di website https://library.vuforia.com/articles/Solution/vuf oria-fusion-supported-devices.html.

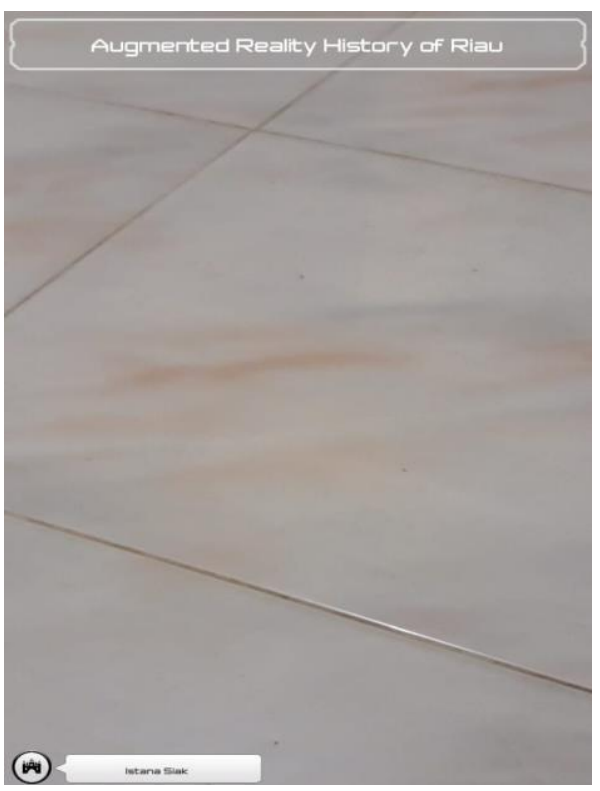

Gambar 4.11 Running Menu Aplikasi 
Pada menu utama dilakukan uji coba dengan melakukan show dan hide menu navigasi lainnya dan setiap button navigasi dapat meload setiap scene dari ke 3 scene utama yang telah dirancang. Scene Istana Siak dapat menampilkan objek Istana Siak secara keseluruhan, objek dapat dipindahkan, dizoom dan dirotate sehingga memudahkan pengguna berinteraksi dengan objek yang ditampilkan pada aplikasi. Dapat dilihat pada gambar 4.12 sebagai berikut:

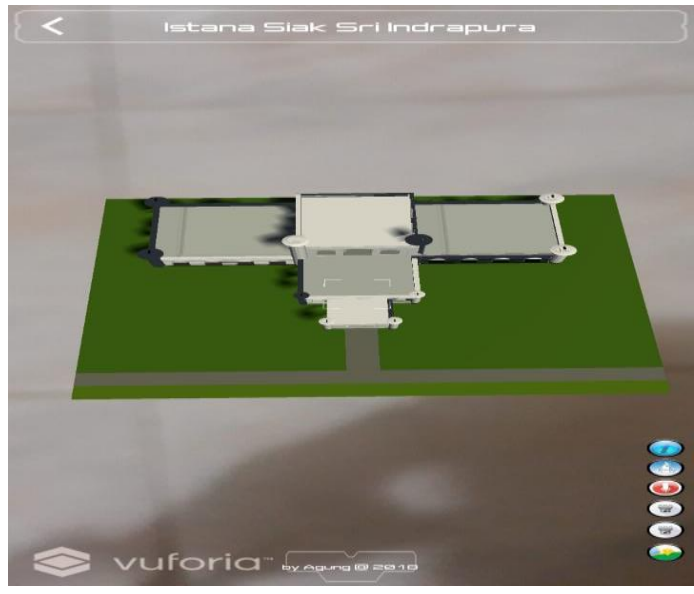

Gambar 4.12 Running Objek Istana Siak Pada Ground Plane

Dengan mengaktifkan menu show lantai 1 pada button navigasi yang terdapat pada sebelah kanan layar maka aplikasi akan menampilkan interior pada lantai 1 Istana Siak. Dapat dilihat pada gambar 4.13 sebagai berikut:

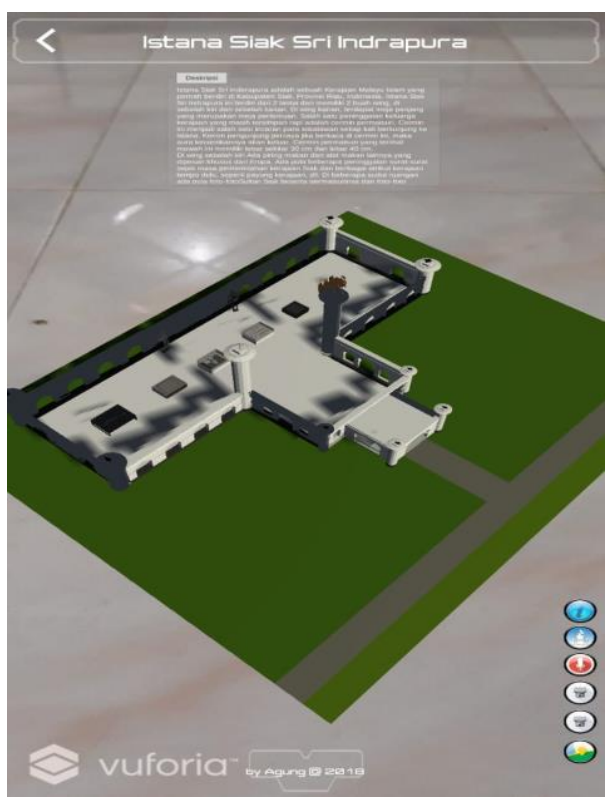

Gambar 4.13 Show dan Hide Lantai 1 Istana
Dengan mengaktifkan menu show lantai 2 pada button navigasi yang terdapat pada sebelah kanan layar maka aplikasi akan menampilkan interior pada lantai 2 Istana Siak. Dapat dilihat pada gambar 4.14 sebagai berikut:

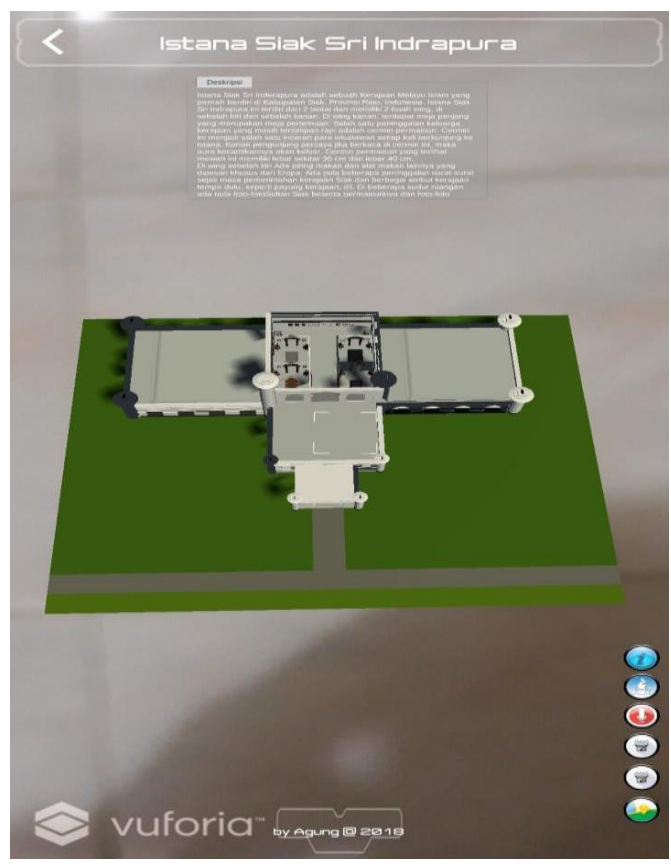

Gambar 4.14 Show dan Hide Lantai 2 Istana

Dengan mengaktikan button deskripsi maka panel deskripsi akan tampil tepat ditengah layar dan juga pengguna juga dapat mendengarkan deskripsi objek dengan voice yang telah disediakan dengan menekan button sound. Untuk melihat objek interior secara khusus pengguna dapat menekan button objek dan aplikasi akan menampilkan objek interior secara khusus, pengguna dapat melihat dengan detail setiap interior yang ada dalamnya dengan mendekatkan kamera pada objek dan dapat mengelilingi objek tersebut. Dapat dilihat pada gambar 4.15 sebagai berikut: 


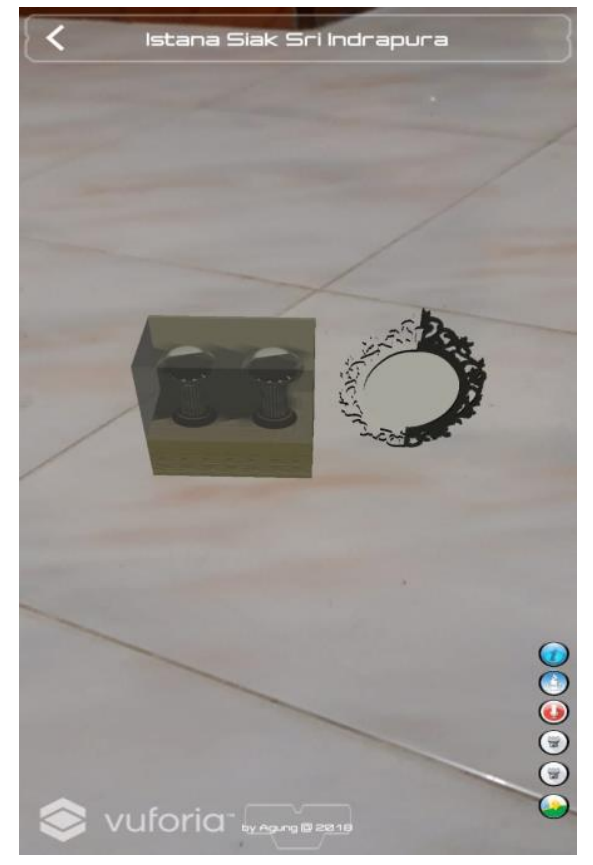

Gambar 4.15 Show dan Hide Objek Interior Istana

\section{Kesimpulan dan saran}

Berdasarkan pengujian dari aplikasi ini dapat disimpulkan bahwa teknologi Augmented Reality 3D Istana Siak sebagai invovasi baru dalam mempromosikan objek wisata yang ada di Riau. Dengan saran pengembangan yaitu pengembangan terhadap tampilan aplikasi, karena tampilan dari aplikasi masih cukup sederhana. Selain itu, dari texture objek 3D yang belum secara detail dari objek yang sebenarnya. Selanjutnya diharapkan adanya penambahan jumlah objek wisata riau yang lebih lengkap serta dilengkapi infomasi dan lokasi.

\section{Daftar Pustaka:}

[1] M. I. Aminah, Siti, "PELAKSANAAN PROMOSI OBJEK WISATA ISTANA SIAK PROVINSI RIAU," JOM FISIP, vol. 2, no. 2, pp. 1-11, 2015.

[2] N. Amaliah, A. Yanu, A. Fianto, and S. P. Yosep, "PERANCANGAN MEDIA PROMOSI PT PETRONIKA SEBAGAI," vol. 4, no. 1, 2015.

[3] A. Labellapansa et al., "Augmented Reality Bangunan Bersejarah Berbasis Android ( Studi Kasus: Istana Siak Sri Indrapura )," vol. 1, no. 2, pp. 1-12, 2017.

[4] A. P. Permana, O. D. Nurhayanti, and K. T. Martono, "Perancangan dan Implementasi Augmented Reality Pemantauan Titik Reklame Kota Semarang Menggunakan QRCode Berbasis ANDROID," vol. 4, no. 2, pp. 295-304, 2016.

[5] G. A. Pradnyana, J. Pendidikan, T. Informatika, U. P. Ganesha, A. Reality, and M. Pengenalan, "PENGEMBANGAN APLIKASI AUGMENTED REALITY MARKERLESS PENGENALAN DAN TEKNIK DASAR BOLA BASKET," vol. 6, 2017.

[6] I. F. Faiztyan, R. R. Isnanto, and E. D. Widianto, "Perancangan dan Pembuatan Aplikasi Visualisasi 3D Interaktif Masjid Agung Jawa Tengah Menggunakan Unity3D," J. Teknol. dan Sist. Komput., vol. 3, no. 2, p. 207, 2015.

[7] R. Gusman and M. E. Apriyani, "Analisis Pemanfaatan Metode Markerless User Defined Target Pada Augmented Reality Sholat Shubuh," vol. 8, no. 1, pp. 64-70, 2016.

[8] Spesifikasi Android Augmented Reality (https://library.vuforia.com)

[9] Siak Sri Indrapura (https://liandamarta.com/2015/05/18/ista na-siak-sri-indrapura) 